\title{
LVI. Remarks on a letter of Professor Daniell contained in the Philosophical Magazine for April
}

\author{
W.R. Grove Esq. M.A. F.R.S.
}

To cite this article: W.R. Grove Esq. M.A. F.R.S. (1842) LVI. Remarks on a letter of Professor Daniell contained in the Philosophical Magazine for April , Philosophical Magazine Series 3, 21:139, 333-335, DOI: 10.1080/14786444208621567

To link to this article: http://dx.doi.org/10.1080/14786444208621567

册 Published online: 01 Jun 2009.

Submit your article to this journal $\lceil\pi$

Џ Article views: 2

Q View related articles $\widetilde{ }$ 
energy of action has been still greater than that produced with the apparatus of Mr. Daniell, since all the silver and the lead contained in the ores, that is to say about one kilogramme of silver and 100 kilogrammes of lead, were extracted in the space of a few hours.

I now leave it to the judgement of the reader which is in the right, Mr. Daniell or myself; and it will then be seen whether filial piety blinded me, or whether I have not rather been actuated by the love of truth.

Paris, July $7,1842$.

LVI. Remarks on a Letter of Professor Daniell contained in the Philosophical Magazine for April. By W. R. Grove, Esq., M.A., F.R.S., Professor of Experimental Philosophy in the London Institution.

To the Eaitors of the Philosophical Magazine and Journal. Gentlemen,

A LLOW me to request your insertion of a few remarks on A letter of Professor Daniell published in your Magazine for April. Absence from London and occupations of other than a scientific nature prevented my noticing it at the time; my attention has been recalled to the matter by its republication in the Annales de Chimie.

A few words at the conclusion of this letter refer to me: after stating that M. Becquerel has inadvertently described my experiments as anterior to Mr. Daniell's, this gentleman goes on to say, "Professor Grove has never spoken of his battery but as the further application of principles which I had previously deduced."

It is perhaps of little moment to the public what principles led me to the construction of the battery in question, but it may be of some moment to me, as should I, by silence, be held to assent to certain principles, I may be accused of contradiction and inconsistency if in any future paper I should state my adherence to others. M. Becquerel, again, in the 5th volume of his 'Traité de l'Electricité, describes my battery as "Pile voltaïque construite d'après les principes exposés dans les chapitres $1^{\mathrm{er}}, \& \mathrm{c} . . "$ these chapters contain the papers of $\mathrm{M}$. Becquerel in respect of which he claims priority to Mr. Daniell. It is obvious, that as M. Becquerel and Mr. Daniell differ in their notions as to the principles of the constant battery, I could not derive my battery from both, and I have looked over my papers on this subject to see whether I have expressly referred it to principles enounced by either 


\section{Prof. Grove's Remarks on a Letter of Prof. Daniell.}

of these philosophers; I cannot see that I have. I have on many occasions mentioned their experiments before my own in the history of the voltaic pile, both as acknowledging their priority and as not wishing to claim what was not my due; probably it is this which has led to a misconception on the part of Mr. Daniell, but I have distinctly stated the idea which immediately led to the construction of my battery in the paper which describes it (Phil. Mag., May 1899). After detailing an experiment with two strips of gold-leaf in nitric and hydrochloric acids separated by a porous diaphragm, and showing that upon contact of the two strips the gold in the hydrochloric acid was dissolved, and that a voltaic current was established, I say, "It now occurred to me, that as gold, platina and two acids gave so powerful an electric current," $a$ fortiori " the same arrangement, with the substitution of zinc for gold, must form a combination more energetic than any yet known:" this was the simple deduction which led to my subsequent experiments. I have in most cases been content to publish experiments with no more of theory than was requisite to connect them; it is a general and I think a just complaint that there are already too many speculations on this subject; but in a letter published in the Philosophical Magazine for Feb. 1839, p. 129, previous to the discovery of my battery, I gave my own notions of the principles of voltaic battëries, notions which in some respects agree with those of $\mathrm{Mr}$. Daniell, but which also suggest some new views of voltaic ace tion. There is one experiment there detailed in which copper is reduced by copper, which had much influence on my subsequent experiments, but which is not explicable by any principles laid down by Mr. Daniell; at the conclusion of this paper I say, " if these principles be correct, very superior combinations may be discovered:" how this prediction has been fulfilled the public is the best judge.

Far be it from me to disclaim any assistance from the experiments of Mr. Daniell or of M. Becquerel; I shall ever retain a grateful recollection of the assistance rendered to my first efforts in science by the Jatter gentleman. I cannot at this distance of time well describe what effect their experiments had upon my mind. In the progress of science it is difficult to define the frequently unperceived effect of prior discoveries upon subsequent experimentalists, but I cannot for many reasons acquiesce in the assertion of Mr. Daniell above quoted.

Mr. Daniell was for a long time attached to the theory of the deposition of metals in the voltaic circuit being the result of a secondary action of the nascent hydrogen, a theory generally adopted until combated by Hisinger and Berzelius; thus 
in his papers, Phil. Trans., 1836, p. 117 et seq., he proceeds to explain his constant battery as dependent upon the removal of that hydrogen by causing it to deoxidate copper: in a subsequent publication (Phil. Trans., 1839) he abandons this view, and considers the deposition of the copper as " a primary result of electrolytic action." This would altogether alter the theory of his battery and of mine. I do not think it is a matter of great consequence which theory be adopted; each has many peculiar difficulties, each tends to many similar conclusions, and either may lead to equally successful experimental results. Theory is valuable as a means not as an end, and that theory of the voltaic battery is in my opinion the best which best collates the observed phænomena and which leads to the discovery of the best voltaic combinations. But although I would hesitate, without more conclusive experiments, in ascribing this superiority to either of these theories, there is another principle of the voltaic battery enounced by Mr. Daniell, as to which, so far from agreeing with him, I must take leave (with every respect for his scientific attainments) to differ toto coelo: it is as to the relative extent of surface to be given to the metals of voltaic combinations. Mr. Daniell has in the Phil. Trans. for 1836, p. 128, and in several subsequent papers, stated that the best theoretical form for a voltaic combination is when the generating metal is arranged with regard to the conducting one as the centre of a sphere to its periphery, and recommends a rod within a cylinder as the nearest practical approximation to such an arrangement; following the authority of Mr. Daniell, I first constructed my batteries of this form, but very soon abandoned it (see Phil. Mag. forOct.1839, p. 288); and I am now convinced, by three years' experience and by repeated experiments, corroborated by the experiments of others, that this is by no means the best form of arrangement, as regards œconomy either of space, time, or material. I believe the old arrangement of equal surfaces to be sufficient for most practical purposes; but the relative size may be considerably modified according to the nature of the electrolytes, the conducting power of the metals, and other circumstances. I cannot enter more fully on this point without writing a paper especially on this subject.

P.S. Since the above was written I have received a paper of Mr. Daniell's just printed, Phil. Trans. 1842, part ii., for which I have to thank the author: it contains a series of experiments on my battery, and with a voltameter of my contrivance. In this paper I see Mr. Daniel alters many of his opinions upon the relative size of the plates in voltaic combinations. 